\title{
Halide $\left(\mathrm{Cl}^{-}, \mathrm{Br}^{-}, \mathrm{I}^{-}\right)$Influence on the Electronic Properties of Macrocyclic Nickel(II) Complexes: Ab-initio DFT Study
}

\author{
Seyed Amir Zarei*, Keivan Akhtari', Keyumars Hassanzadeh, Mohammad Piltan, \\ Saadi Saaidpour, and Marjan Abedi ${ }^{*}$ \\ Department of Chemistry, Faculty of Science, Sanandaj Branch, Islamic Azad University, Sanandaj, Iran. \\ ${ }^{*}$ E-mail: Seyedamirzarei@yahoo.com \\ 'Department of Physics, Sharif University of Technology, P.O.Box 11365-9161, Tehran, Iran \\ Department of Chemistry, Faculty of Science, University of Mohaghegh Ardabili, Ardabil, Iran
} (Received January 16, 2013; Accepted March 19, 2013)

\begin{abstract}
The geometry structures of hexa-coordinated [NiLX]X complexes $\left(\mathrm{X}=\mathrm{Cl}^{-}, \mathrm{Br}^{-}, \mathrm{I}^{-}\right)\{\mathrm{L}=8,9,18,19$-tetrahydro7H,17H-dibenzo[f,o] [1,5,9,13] dioxadiaza cyclohexadecine-8,18-diol $\}$ are optimized by density functional theory (DFT) using B3LYP/LANL2DZ. The calculated geometric parameters are in good agreement with the corresponding experimental values. Calculation results about these complexes show that dipole moment decreases, and the energy levels of HOMOs descend from iodo-complex to chloro-complex. The energy levels of HOMOs descend gently from iodo-complex to chloro-complex, while the energy levels of LUMOs in the present complexes are almost similar; therefore the energy gapes between HOMOs and LUMOs increased from iodo-complex to chloro-complex.
\end{abstract}

Key words: Density functional theory, Nickel(II) complexes, Macrocyclic Schiff base, Halide, Electronic properties

\section{INTRODUCTION}

Macrocyclic ligands, in particular, those containing functional pendant arms and their metal complexes have been frequently investigated due to their potential applications in different fields such as: catalysts, ${ }^{1-3}$ discovery of new chemical sensors and optoelectronic devices, ${ }^{4-8}$ advancement of bioinorganic chemistry to understand the chemistry of metallo-protein and produce useful new biomimetic reactions $^{9-12}$ and continuing development of basic coordination chemistry. ${ }^{13-15}$ It has been found that the kind of central metal, its coordination environment, type of donor atoms and the conformation of macrocyclic ligands can influence these properties. ${ }^{16}$ The precise insight for synthesizing such unique macrocyclic complexes is dependent on the precise understanding about electronic structure of these compounds which could lead to reach new compounds with high performance in the above-mentioned applications. ${ }^{17-21}$ Therefore, molecular orbitals (particularly, HOMO and LUMO) and their properties such as energy that are very important parameters for quantum chemistry would be very useful for physicists and chemists. ${ }^{22-26}$ In our previous works, ${ }^{27,28}$ we have reported the synthesis of some nickel(II) complexes of two alcohol pendant arms macrocyclic potentially hexadentate ligand(L) (Scheme 1) with formula $[\mathrm{NiLX}] \mathrm{X}\left(\mathrm{X}=\mathrm{Cl}^{-}, \mathrm{Br}^{-}, \mathrm{I}^{-}\right)$and their molecular structures.

In the present study, we report a theoretical research on the electronic structures of previously reported [NiLX]X $\left(\mathrm{X}=\mathrm{Cl}^{-}, \mathrm{Br}^{-}, \mathrm{I}^{-}\right)$complexes and the influence of coordinated halides on their electronic structures, using DFTB3LYP/LANL2DZ.

\section{COMPUTAIONAL DETAILS}

The geometrical optimization and single point energy calculation were carried out using GAUSSIAN $03^{29}$ program. The density functional theory (DFT) with Unrestricted Becke's three parameters(B3) exchange functional along with the Lee-Yang-Parr(LYP) non-local correlation functional (UB3LYP) ${ }^{31,32}$ the Los Alamos LANL2DZ ${ }^{31-33}$ effective core pseudo-potentials (ECP) and valence double Zeta basis set.<smiles>COc1ccccc1C=NCC(O)COc1ccccc1C=NCC(O)CC(O)CO</smiles>

Scheme 1. 


\section{RESULTS AND DISCUSSION}

The octahedral $[\mathrm{NiLX}]^{+}\left(\mathrm{X}=\mathrm{Cl}^{-}, \mathrm{Br}^{-}, \mathrm{I}^{-}\right)$cation complexes were optimized and the subsequent calculations were continued by means of DFT-B3LYP. The optimized geometry of arbitrarily chosen $[\mathrm{NiLBr}]^{+}$cation complex is shown in Fig. 1. Also, the ORTEP view of [NiLBr]Br com-

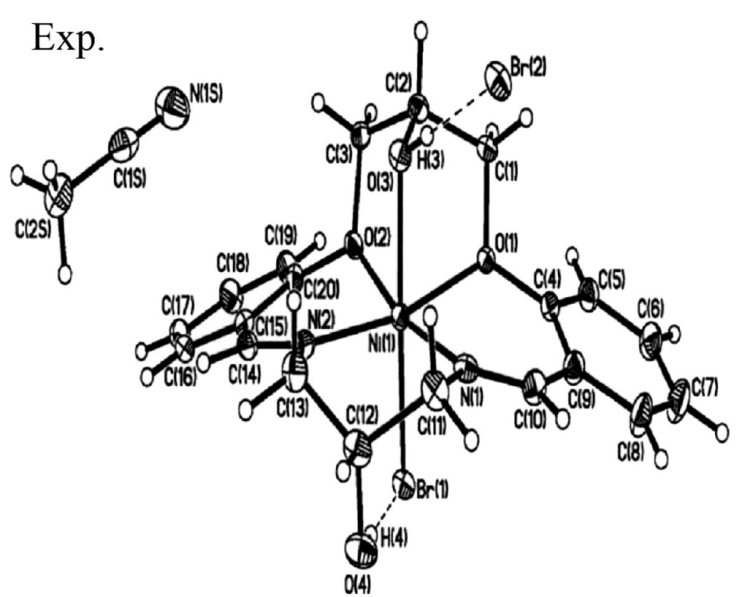

plex from ref 28 is brought in Fig. 1 to draw a comparison between theoretical and experimental geometric parameters. Selected bond lengths and bond angles obtaining from optimized structures of $[\mathrm{NiLX}]^{+}$cation complexes with those of experimentally determined by single crystal X-ray diffraction taken from refs 27 and 28 are summarized in Table 1. According to Table 1, most theoretical geo-

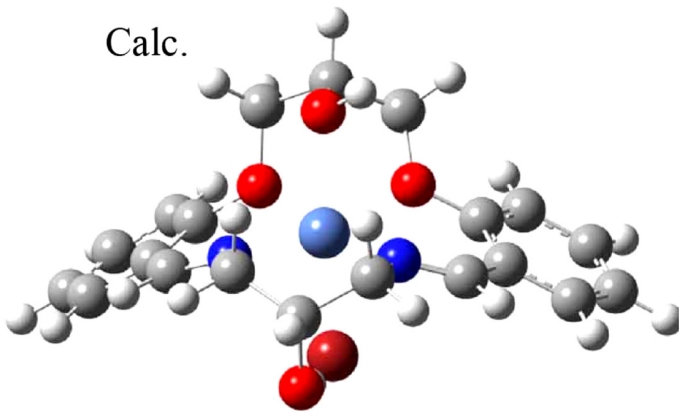

Figure 1. Optimized geometry of $[\mathrm{NiLBr}]^{+}$by DFT-B3LYP/LANL2DZ (right) and [NiLBr]Br ORTEP view (left) from ref 28.

Table 1. Selected theoretical (by DFT-B3LYP/LANL2DZ) and experimental ${ }^{27,28}$ (by X-ray) bond lengths and bond angles of [NiLX]X (X $\left.=\mathrm{Cl}^{-}, \mathrm{Br}^{-}, \mathrm{I}^{-}\right)$complexes

\begin{tabular}{|c|c|c|c|c|c|c|}
\hline & \multicolumn{2}{|c|}{$[\mathrm{NiLCl}] \mathrm{Cl}$} & \multicolumn{2}{|c|}{$[\mathrm{NiLBr}] \mathrm{Br}$} & \multicolumn{2}{|c|}{ [NiLI]I } \\
\hline & Exp. & Calc. & Exp. & Calc. & Exp. & Calc. \\
\hline \multicolumn{7}{|l|}{ Bond Length $(\AA)$} \\
\hline $\mathrm{Ni}(1)-\mathrm{N}(1)$ & 1.990 & 2.054 & 2.004 & 2.054 & 2.005 & 2.055 \\
\hline $\mathrm{Ni}(1)-\mathrm{N}(2)$ & 2.021 & 2.041 & 2.012 & 2.041 & 1.999 & 2.042 \\
\hline $\mathrm{Ni}(1)-\mathrm{O}(1)$ & 2.073 & 2.122 & 2.078 & 2.123 & 2.064 & 2.126 \\
\hline $\mathrm{Ni}(1)-\mathrm{O}(2)$ & 2.069 & 2.110 & 2.074 & 2.112 & 2.066 & 2.117 \\
\hline $\mathrm{Ni}(1)-\mathrm{O}(3)$ & 2.118 & 2.272 & 2.110 & 2.288 & 2.128 & 2.313 \\
\hline Ni(1)-X(1) & 2.345 & 2.370 & 2.487 & 2.537 & 2.733 & 2.734 \\
\hline \multicolumn{7}{|l|}{ Angles $\left(^{\circ}\right)$} \\
\hline$N(1)-N i(1)-N(2)$ & 99.20 & 100.36 & 100.61 & 100.17 & 99.55 & 100.01 \\
\hline $\mathrm{N}(1)-\mathrm{Ni}(1)-\mathrm{O}(1)$ & 88.30 & 85.81 & 88.41 & 85.74 & 87.48 & 85.55 \\
\hline$N(2)-\mathrm{Ni}(1)-\mathrm{O}(1)$ & 170.20 & 168.69 & 167.81 & 168.08 & 172.52 & 166.96 \\
\hline $\mathrm{N}(1)-\mathrm{Ni}(1)-\mathrm{O}(2)$ & 169.30 & 169.49 & 168.04 & 169.01 & 167.28 & 167.97 \\
\hline $\mathrm{N}(2)-\mathrm{Ni}(1)-\mathrm{O}(2)$ & 88.20 & 87.50 & 89.26 & 87.33 & 88.26 & 87.12 \\
\hline $\mathrm{O}(1)-\mathrm{Ni}(1)-\mathrm{O}(2)$ & 83.59 & 85.32 & 80.90 & 85.48 & 84.38 & 85.55 \\
\hline $\mathrm{N}(1)-\mathrm{Ni}(1)-\mathrm{O}(3)$ & 95.69 & 96.36 & 94.66 & 95.70 & 90.79 & 94.58 \\
\hline $\mathrm{N}(2)-\mathrm{Ni}(1)-\mathrm{O}(3)$ & 94.44 & 97.15 & 92.45 & 96.60 & 101.09 & 95.70 \\
\hline $\mathrm{O}(1)-\mathrm{Ni}(1)-\mathrm{O}(3)$ & 78.50 & 72.60 & 78.55 & 72.38 & 76.06 & 71.97 \\
\hline $\mathrm{O}(2)-\mathrm{Ni}(1)-\mathrm{O}(3)$ & 75.84 & 75.58 & 78.03 & 75.31 & 77.79 & 74.95 \\
\hline$N(1)-N i(1)-X(1)$ & 94.75 & 92.10 & 92.28 & 93.15 & 92.77 & 94.53 \\
\hline$N(2)-N i(1)-X(1)$ & 93.65 & 92.70 & 93.34 & 93.83 & 91.10 & 95.19 \\
\hline $\mathrm{O}(1)-\mathrm{Ni}(1)-\mathrm{X}(1)$ & 91.94 & 96.56 & 94.47 & 96.18 & 91.14 & 96.12 \\
\hline $\mathrm{O}(2)-\mathrm{Ni}(1)-\mathrm{X}(1)$ & 92.55 & 94.51 & 93.89 & 94.37 & 97.14 & 94.46 \\
\hline $\mathrm{O}(3)-\mathrm{Ni}(1)-\mathrm{X}(1)$ & 165.60 & 165.64 & 169.99 & 164.91 & 166.57 & 164.37 \\
\hline
\end{tabular}


Table 2. DFT-B3LYP theoretical and experimental intermolecular hydrogen bond lengths $(\AA)$ between coordinated halide and uncoordinated alcohol pendant arm in [NiLX]X complexes

\begin{tabular}{lcc}
\hline Complex & $\begin{array}{c}\text { X-ray Crystallographic } \\
\text { Data }\end{array}$ & $\begin{array}{c}\text { UB3LYP/LANL2DZ } \\
\text { Data }\end{array}$ \\
\hline$[\mathrm{NiLCl}] \mathrm{Cl}$ & 2.471 & 2.295 \\
{$[\mathrm{NiLBr}] \mathrm{Br}$} & 2.539 & 2.478 \\
{$[\mathrm{NiLI}] \mathrm{I}$} & 2.821 & 2.694 \\
\hline
\end{tabular}

metric parameters for $[\mathrm{NiLX}]^{+}$species are in good agreement with corresponding experimental data. The observed remarkable deviations in some cases may rise because of the following reasons: the selection of calculation method, and the neglect of intermolecular interactions and crystal packing effects. It should be pointed out that uncoordinated alcohol pendant arm, coordinated alcohol pendant arm and halides have participated in intermolecular interactions according to refs 27 and 28 which are ignored in current calculations that are based on the geometry in the gas phase configuration of $[\mathrm{NiLX}]^{+}$cation complexes.

Herein, in order to find out the influence of intermolecular interactions, DFT-B3LYP theoretical and experimental (from refs 27 and 28) intramolecular hydrogen bond lengths between coordinated halide and uncoordinated alcohol pendant arm in $[\mathrm{NiLX}]^{+}$cation complexes are illustrated in Table 2, and DFT-B3LYP optimized structure involving this interaction for $[\mathrm{NiLI}]^{+}$cation complex is shown in Fig. 2. By comparison of these data, it can be concluded that intramolecular hydrogen bond interaction in gas phase is shortened in the absence of intermolecular interactions which have been constructed by agents such as coordinated halide and uncoordinated alcohol pendant arm in $[\mathrm{NiLX}]^{+}$cation complexes in the solid phase. ${ }^{27,28}$

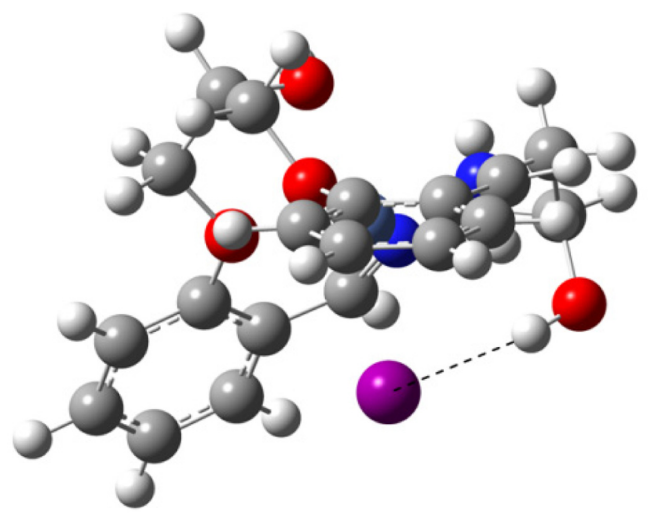

Figure 2. DFT-B3LYP optimized structure involving intramolecular hydrogen bond between iodo and uncoordinated hydroxyl group for $[\mathrm{NiLI}]^{+}$.

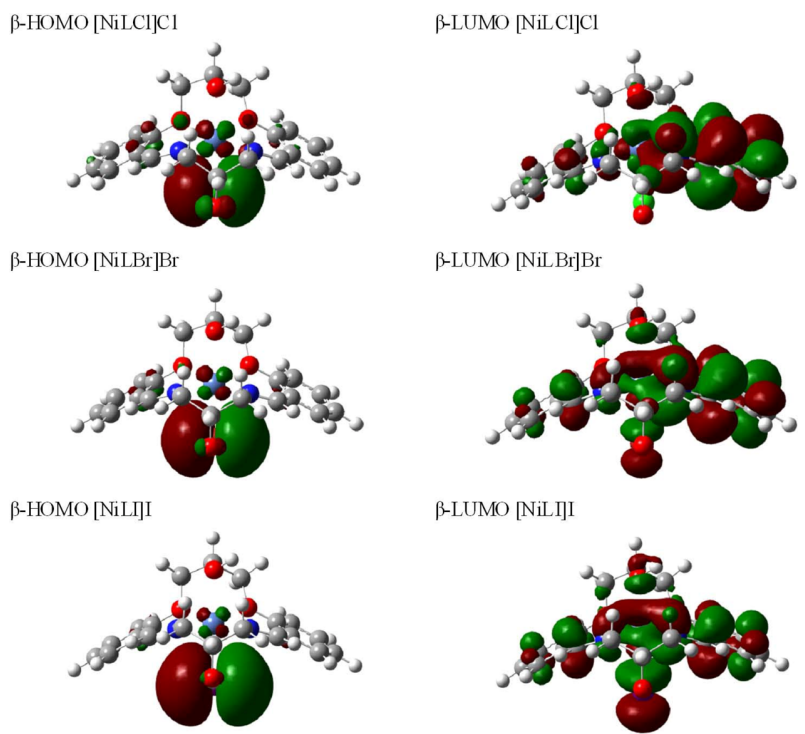

Figure 3. Plots of $\beta$-Frontier molecular orbitals for $[\mathrm{NiLX}]^{+}$ $\left(\mathrm{X}=\mathrm{Cl}^{-}, \mathrm{Br}^{-}, \mathrm{I}^{-}\right)$cation complexes.
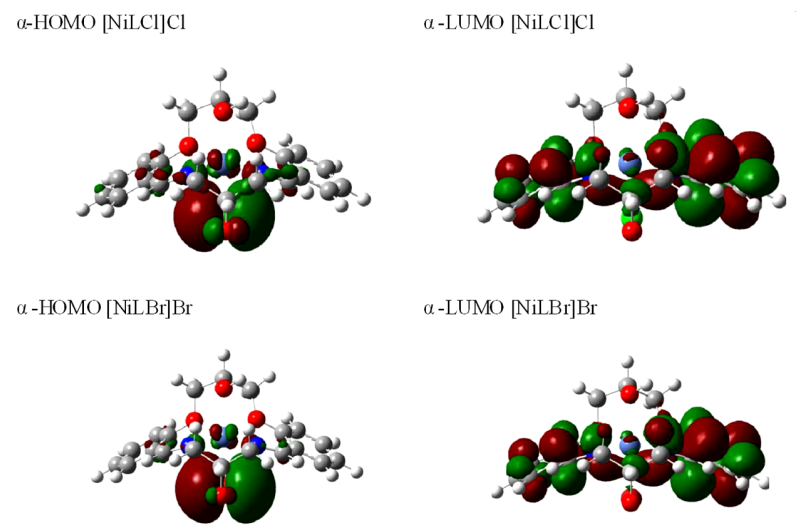

$\alpha-L U M O[N i L B r] B r$

a-HOMO [NiLI]
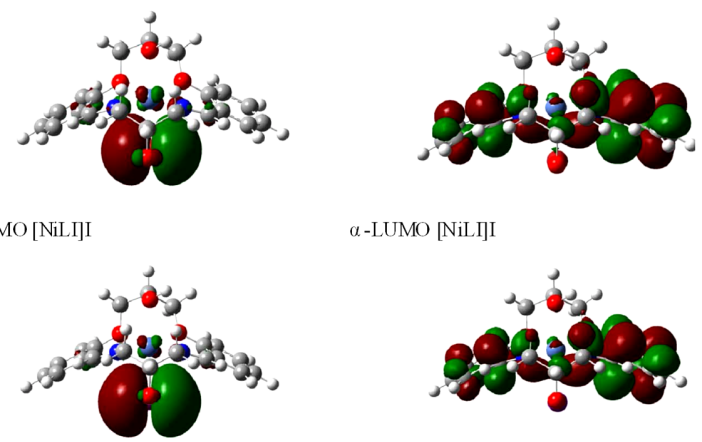

$a$-LUMO [NiLПI

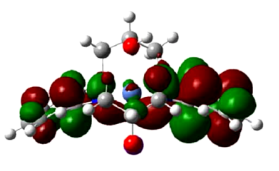

Figure 4. Plots of $\alpha$-Frontier molecular orbitals for $[\mathrm{NiLX}]^{+}$ $\left(\mathrm{X}=\mathrm{Cl}^{-}, \mathrm{Br}^{-}, \mathrm{I}^{-}\right)$cation complexes.

Frontier molecular orbitals of $[\mathrm{NiLX}]^{+}$cation complexes are investigated to find out the halide influence on electronic structure of these complexes. The highest occupied molecular orbitals (HOMO) and the lowest unoccupied molecular orbitals (LUMO) of these systems are shown in Figs. 3 and 4 and also some of the important calculated structural parameters of the complexes are summarized in Table 3. For clarity, orbital contributions of the donor atoms in the coordination environment along with nickel ion for all complexes in the Frontier MOs have also 
Table 3. Some calculated structural parameters of $[\mathrm{NiLX}]^{+}\left(\mathrm{X}=\mathrm{Cl}^{-}, \mathrm{Br}^{-}, \mathrm{I}^{-}\right)$cation complexes

\begin{tabular}{lcccccc}
\hline Complex & $\begin{array}{c}\alpha-H O M O \\
(\mathrm{eV})\end{array}$ & $\begin{array}{c}\alpha-L U M O \\
(\mathrm{eV})\end{array}$ & $\begin{array}{c}\alpha \text {-HOMO- } \alpha \text {-LUMO } \\
\text { Gap }(\mathrm{eV})\end{array}$ & $\begin{array}{c}\beta-H O M O \\
(\mathrm{eV})\end{array}$ & $\begin{array}{c}\beta-\mathrm{LUMO} \\
(\mathrm{eV})\end{array}$ & $\begin{array}{c}\beta-H O M O-\beta-L U M O \\
\text { Gap }(\mathrm{eV})\end{array}$ \\
\hline$[\mathrm{NiLCl}] \mathrm{Cl}$ & -9.06 & -5.05 & 4.01 & -8.98 & -5.11 & 3.87 \\
{$[\mathrm{NiLBr}] \mathrm{Br}$} & -8.61 & -5.08 & 3.53 & -8.54 & -5.16 & 3.38 \\
{$[\mathrm{NiLI}] \mathrm{I}$} & -8.20 & -5.12 & 3.08 & -8.13 & -5.24 & 2.89 \\
\hline
\end{tabular}

Table 4. Frontier molecular orbitals relative compositions of coordination environment atoms for $[\mathrm{NiLX}]^{+}\left(\mathrm{X}=\mathrm{Cl}^{-}, \mathrm{Br}^{-}, \mathrm{I}^{-}\right)$cation complexes

\begin{tabular}{|c|c|c|c|c|c|c|c|}
\hline \multirow{2}{*}{ Complex } & \multicolumn{7}{|c|}{ Composition \% } \\
\hline & $\mathrm{Ni}$ & $\mathrm{O}_{1}$ & $\mathrm{O}_{2}$ & $\mathrm{O}_{3}$ & $\mathrm{~N}_{1}$ & $\mathrm{~N}_{2}$ & $\mathrm{X}$ \\
\hline \multicolumn{8}{|c|}{$\alpha-\mathrm{HOMO}$} \\
\hline$[\mathrm{NiLCl}] \mathrm{Cl}$ & 9.69 & 0.86 & 1.13 & 0.49 & 7.35 & 6.45 & 22.30 \\
\hline$[\mathrm{NiLBr}] \mathrm{Br}$ & 9.44 & 1.03 & 1.12 & 0.57 & 6.68 & 5.76 & 25.96 \\
\hline [NiLI]I & 8.70 & 1.34 & 1.36 & 0.60 & 5.60 & 5.81 & 27.78 \\
\hline \multicolumn{8}{|c|}{$\alpha$-LUMO } \\
\hline [NiLCl]Cl & 3.58 & 2.36 & 1.12 & 1.14 & 9.00 & 4.50 & 1.50 \\
\hline [NiLBr]Br & 3.56 & 2.23 & 1.13 & 1.14 & 8.71 & 4.72 & 1.49 \\
\hline [NiLI]I & 3.95 & 2.19 & 1.14 & 1.16 & 8.88 & 4.74 & 1.62 \\
\hline \multicolumn{8}{|c|}{$\beta$-HOMO } \\
\hline$[\mathrm{NiLCl}] \mathrm{Cl}$ & 11.25 & 2.63 & 2.64 & 2.93 & 4.11 & 3.31 & 23.04 \\
\hline$[\mathrm{NiLBr}] \mathrm{Br}$ & 11.11 & 2.67 & 2.52 & 2.21 & 4.20 & 3.21 & 26.32 \\
\hline [NiLI]I & 10.47 & 2.70 & 2.69 & 1.55 & 3.69 & 3.48 & 27.91 \\
\hline \multicolumn{8}{|c|}{$\beta$-LUMO } \\
\hline [NiLCl]Cl & 9.34 & 2.87 & 1.66 & 0.86 & 9.79 & 2.17 & 1.35 \\
\hline [NiLBr]Br & 11.71 & 2.51 & 2.05 & 0.93 & 8.33 & 2.73 & 2.56 \\
\hline [NiLI]I & 15.08 & 2.42 & 2.51 & 1.06 & 6.11 & 4.31 & 4.48 \\
\hline
\end{tabular}

been analyzed and shown in Table 4.

According to Figs. 3 and 4 and Tables 3 and 4, it can be observed that the contributions of halides in $\alpha$-LUMO of the complexes are similar and $\beta$-LUMOs are different in contribution in a few percent so that the magnitude of contribution of halide approximately becomes twofold in $\beta$ LUMOs from chloro-complex to iodo-complex. Whereas, the contributions of halides in both $\alpha$-HOMOs and $\beta$-HOMOs are different a few, and their values increased from chlorocomplex to iodo-complex. According to Table 3, the energy

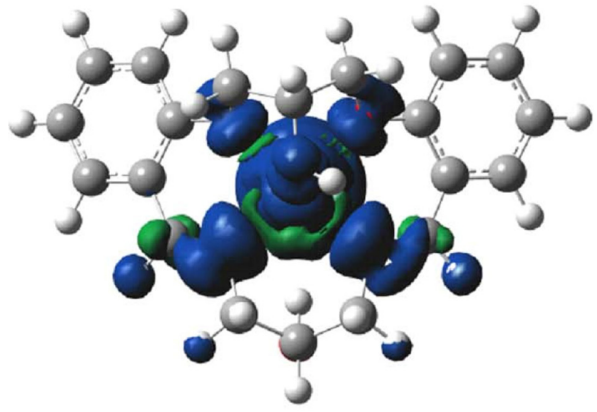

(a) levels of HOMOs descend gently from iodo-complex to chloro-complex, while the energy levels of LUMOs in the present complexes are almost similar. Changing in LUMOs energy levels throughout these complexes is little due to the lower contribution of halides in these orbitals, whereas changing in HOMOs energy levels including higher contribution of halides is considerable.

The spin density distribution for nickel complexes was calculated to view the electronic structure which illustrated similar pattern in all complexes. For example, Fig. 5 shows

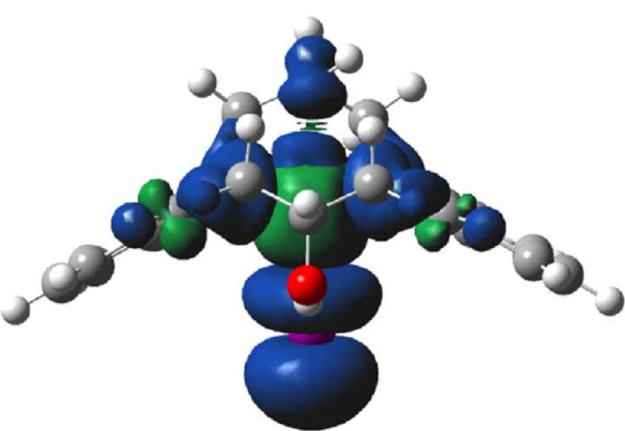

(b)

Figure 5. Spin density distribution of iodo complex (a) top and (b) front view. The hydrogen atoms are omitted for clarity. Positive and negative values are represented as green and blue surfaces, respectively. 
Table 5. Spin densities on nickel and halogen atoms and Dipole moment values for $[\mathrm{NiLX}]^{+}\left(\mathrm{X}=\mathrm{Cl}^{-}, \mathrm{Br}^{-}, \mathrm{I}^{-}\right)$cation complexes

\begin{tabular}{lccc}
\hline Complex & Spin density on nickel & Spin density on halogen & Dipole moment $(\mu)($ Debye $)$ \\
\hline$[\mathrm{NiLCl}] \mathrm{Cl}$ & 1.616 & 0.144 & 10.58 \\
{$[\mathrm{NiLBr}] \mathrm{Br}$} & 1.595 & 0.170 & 11.49 \\
{$[\mathrm{NiLI}] \mathrm{I}$} & 1.571 & 0.201 & 12.39 \\
\hline
\end{tabular}

spin density distribution of iodo-complex. The difference between spin density values for nickel and halogen in the complexes is considerable (see Table 5).

Table 5 also gives the calculated dipole moment in the nickel complexes. It should be pointed out that the dipole moment of the complexes is controlled by the axial section in coordination environment of the structures $(\mathrm{O}(3)-$ Ni(1)-X(1), see Fig. 1) and increasing the electronegativity of the halogen could make the dipole moments of complexes increased due to higher ability of charge separation between the nickel and halogen (Table 5).

\section{CONCLUSIONS}

Theoretical investigation by using DFT-B3LYP/LANL2DZ in $[\mathrm{NiLX}] \mathrm{X}\left(\mathrm{X}=\mathrm{Cl}^{-}, \mathrm{Br}^{-}, \mathrm{I}^{-}\right)$complexes have been carried out. The results of structural parameters illustrate that dipole moment decreases, the energy levels of HOMOs descend and the energy gap between HOMO and LUMO increases from iodo-complex to chloro-complex, while the energy levels of LUMOs in the present complexes are almost similar.

Acknowledgments. We are grateful to Sanandaj Branch, Islamic Azad University Council for the financial support of this research. And the publication cost of this paper was supported by the Korean Chemical Society.

\section{REFERENCES}

1. Felix, V.; Santos, T. M.; Madureira, J.; Mirante, F.; Quintal, S.; Goodfellow, B. J.; Santana-Marques, M. G.; Pedrosa, J.; Drew, M. G. B.; Calhorda, M. J. Inorg. Chim. Acta 2003, 356, 335.

2. Burkholder, E.; Heirtzler, F.; Orian, L.; Ouellette, W.; Zubieta, J. Polyhedron 2008, 27, 3700.

3. Bazzicalupi, C.; Bencini, A.; Berni, E.; Vaira, M. D. Inorg. Chim. Acta 2005, 358, 77.

4. Bradbury, A. J.; Lincoln, S. F.; Wainwright, K. P. New J. Chem. 2008, 32, 1500.

5. Jiang, P.; Guo, Z. Coord. Chem. Rev. 2004, 248, 205.

6. Dey, K. R.; Wong, B. M.; Hossain, M. A. Tetrahedron Lett. 2010, 51, 1329.

7. Dudek, L.; Grolik, J.; Kazmierska, A.; Szneler, E.; Eilmes, A.; Stadnicka, K.; Eilmes, J. Tetrahedron Lett. 2011, 52, 3597.
8. Balanay, M. P.; Kim, D. H. Phys. Chem. Chem. Phys. 2008, 10, 5121.

9. Balandina, A.; Mamedov, V.; Latypov, S. J. Mol. Struct. 2008, 889, 89.

10. Chaudhary, A.; Patra, R.; Rath, S. P. Eur. J. Inorg. Chem. 2010, 5211.

11. Newell, M.; Thomas, J. A. Dalton Trans. 2006, 705.

12. Finazzo, C.; Calle, C.; Stoll, S.; Doorslaer, S. V.; Schweiger, A. Phys. Chem. Chem. Phys. 2006, 8, 1942.

13. Wichmann, K.; Antonioli, B.; Sohnel, T.; Wenzel, M.; Gloe, K.; Price, J. R.; Lindoy, L. F.; Blake, A. J.; Schroder, M. Coord. Chem. Rev. 2006, 250, 2987.

14. Archibald, S. J. Annu. Rep. Prog. Chem. Sect. A 2007, 103, 264.

15. Bazzicalupi, C.; Bencini, A.; Bianchi, A.; Danesi, A.; Faggi, E.; Giorgi, C.; Santarelli, S.; Valtancoli, B. Coord. Chem. Rev. 2008, 252, 1052.

16. Bradshaw, J. S.; Karkowiak, K. E.; Izatt, R. M. Aza-crown macrocycles; John Wiley \& Sons: New York, 1993.

17. Trotter, K. D.; Reglinski, J.; Robertson, K.; Forgie, J. C.; Parkinson, J. A.; Kennedy, A. R.; Armstrong, D. R. Sowden, R. J; Spickett, C. M. Inorg. Chim. Acta 2009, 362, 4065.

18. Soto, D.; Guadarrama, P. J. Comput. Chem. 2004, 25, 1215.

19. Zheng, X.; Wang, X.; Yi, S.; Wang, N.; Peng, Y. J. Comput. Chem. 2009, 30, 2674.

20. Mattias, B. A.; Eng, P.; Pettersson, K.; Winters, M. U. Phys. Chem. Chem. Phys. 2007, 9, 5847.

21. Albrett, A. M.; Conradie, J.; Ghosh, A.; Brothers, P. J. Dalton Trans. 2008, 4464.

22. Harrington, J. M.; Jones, S. B.; Derveer, D. J. V.; Bartolotti, L. J.; Hancock, R. D. Inorg. Chim. Acta 2009, 362, 1122.

23. Janzen, D. E.; Derveer, D. G. V.; Mehne, L. F.; Grant, G. J. Inorg. Chim. Acta 2010, 364, 55.

24. Yang, Y. Polyhedron 2012, 33, 310.

25. Lu, T.; Xiang, M.; Wang, H. He, T.; Chen, D. J. Mol. Struct. THEOCHEM 2008, 860, 141.

26. Munoz-Castro, A.; Carey, D. M.; Arratia-Perez, R. Polyhedron 2010, 29, 45.

27. Khandar, A. A.; Hosseini-Yazdi, S. A.; Khatamian, M.; McArdle, P.; Zarei, S. A. Polyhedron 2007, 26, 33.

28. Khandar, A. A.; Hosseini-Yazdi, S. A.; Khatamian, M.; Zarei, S. A. Polyhedron 2010, 29, 995.

29. Frisch, M. J.; et al. GAUSSIAN, Wallingford, CT, 2004.

30. Becke, A. D. J. Chem. Phys. 1993, 98, 5648.

31. Lee, C.; Yang, W.; Parr, R. G. Phys. Rev. 1988, B37, 785.

32. Hay, P. J. J. Chem. Phys. 1985, 82, 270.

33. Hay, P. J.; Wadt, W. R. J. Chem. Phys. 1985, 82, 299. 